\title{
A COMPREENSÃO DO SIGNIFICADO CULTURAL DO ANEURISMA CEREBRAL E DO TRATAMENTO ATRIBUÍDOS PELO PACIENTE E FAMILIARES: UM ESTUDO ETNOGRÁFICO*
}

\author{
Maria Helena Pinto** \\ Márcia Maria Fontão Zago***
}

PINTO, M.H.; ZAGO, M.M.F. A compreensão do significado cultural do aneurisma cerebral e do tratamento atribuídos pelo paciente e familiares: um estudo etnográfico. Rev.latino-am.enfermagem, Ribeirão Preto, v. 8, n. 1, p. 5156 , janeiro 2000 .

Este trabalho consiste de um estudo etnográfico descritivo, com 13 pacientes acometidos pelo aneurisma cerebral e seus familiares, com o objetivo de compreender o significado da doença e do tratamento. Os dados foram coletados por entrevistas e observações durante a hospitalização e depois da alta, no ambulatório e na residência. O tema central obtido do estudo foi “Tinha que ser para mim. Deus sabe o que faz". Este tema revela uma interpretação religiosa para a doença e uma fundamentação mágica para o tratamento. Assim, o aneurisma cerebral é interpretado como uma doença material (corpo) e uma doença espiritual (alma).

UNITERMOS: aneurisma cerebral, cultura, paciente, cirurgia

\section{INTRODUÇÃO}

O interesse pelo tema surgiu da minha vivência junto a clínica cirúrgica, especificamente com os pacientes/familiares acometidos pelo aneurisma cerebral, onde pude observar suas diferentes reações quanto ao processo da doença e tratamento do aneurisma cerebral.

MELLO et al. (1992) em uma investigação realizada em 1985, relatam que no Hospital de Base de Brasília - DF, $61 \%$ dos Acidentes Vasculares Cerebrais foram causados por ruptura de aneurisma.

Os aneurismas intracranianos caracterizam-se por uma dilatação localizada e anormal na parede das artérias, situadas geralmente no polígono arterial de Wills. Eles podem ser congênitos, traumáticos, arterioescleróticos, por alongamento séptico ou formação de bolsa para fora das paredes do vaso (HOLANDA et al., 1995; BLACK \& MATASSARIN-JACOBS, 1996).

DAMIANI et al. (1997) afirmam que a hipertensão arterial, obesidade, cardiopatia, diabetes mélito, hipercolesterolemia, tabagismo, etilismo crônico, hiperuricemia, os contraceptivos orais e discrasias sangüíneas são importantes fatores de risco para o acidente vascular cerebral e BLACK \& MATASSARINJACOBS (1996) inclui também, o traumatismo craniano e o uso da cocaína.
A maioria dos pacientes que apresentam a ruptura de aneurisma esta faixa etária de 30 a 60 anos de idade, sendo o pico de incidência máxima na quinta década de vida, e com ocorrência maior entre as mulheres (FOX, 1990; HOLANDA et al., 1995).

O paciente tipicamente, relata um início agudo de cefaléia intensa, em geral a pior cefaléia que o paciente já experimentou, seguido de perda ou não da consciência. Algumas vezes, a perda da consciência é súbita e não acompanhada por cefaléia. O quadro normalmente ocorre durante um exercício físico. Ao exame, sinais de irritação da meninge são comuns, como fotofobia, rigidez de nuca e febre baixa (BLACK \& MATASSARIN, 1996).

A maioria dos sinais e sintomas de ruptura de aneurisma cerebral é o resultado do extravasamento agudo de sangue dentro do espaço subaracnóideo. A hipertensão arterial e o estresse constante talvez sejam causas de ruptura de aneurisma que causa aumento da força do fluxo sangüíneo, particularmente na bifurcação entre as artérias, onde é a localização mais comum dos aneurismas, o que aumenta a sua gravidade, independente do volume do aneurisma.

As principais complicações após a ruptura de aneurismas intracranianos são: ressangramento, vasoespasmos, hiponatremia, hidrocefalia, meningite séptica e hematoma intracraniano (FOX, 1990). Essa

\footnotetext{
* Este trabalho é parte da Dissertação de Mestrado apresentada a Escola de Enfermagem de Ribeirão Preto da Universidade de São Paulo, em novembro de 1998

** Enfermeira. Professor do Departamento de Enfermagem Geral da Faculdade de Medicina de São José do Rio Preto-SP

*** Enfermeira. Professor Doutor do Departamento de Enfermagem Geral e Especializada da Escola de Enfermagem de Ribeirão Preto da Universidade de São Paulo. Orientadora do estudo
} 
mudança inesperada da condição do cliente, altera o seu estilo de vida, sendo a hospitalização necessária por um período mais longo.

O prognóstico dos doentes após o sangramento de aneurisma intracraniano está associado à gravidade do sangramento inicial, a ocorrência de ressangramento e a ocorrência de vasoespasmo.

Esses pacientes devem ser internados para observação e tratamento específico.

O cuidado de enfermagem ao paciente com aneurisma cerebral é uma tarefa complexa pois, o início súbito de uma doença gera sentimentos de insegurança e ansiedade no paciente e em sua família, levando a indagações como: O que aconteceu? Porque isso aconteceu comigo? Será perigoso?

O mal súbito, a descoberta do diagnóstico e a forma de cura é um processo que deve ser realizado transformando os sinais e sintomas iniciais em uma condição identificável culturalmente: um nome, uma causa conhecida, um tratamento e um prognóstico.

A enfermagem, durante todo o processo de diagnóstico e intervenção, tem como responsabilidade desenvolver a interação com o cliente/paciente, com a intenção de solucionar os problemas emergentes que esteja alterando a sua integridade. Assim, os aspectos fisiológicos do cuidado de enfermagem são os de maior divulgação na literatura.

As informações sobre o contexto sóciocultural, com a compreensão de suas atitudes e mesmo o que representa uma possível mudança de estilo de vida para o paciente/família acabam ficando no esquecimento.

Como já foi referido por ZAGO (1994), a assistência de enfermagem ao paciente cirúrgico deve fundamentar-se também na compreensão dos sentimentos, valores, significados e crenças dos clientes e suas famílias, para o "cuidar".

Diante do exposto este estudo tem como objetivo "compreender o significado do aneurisma cerebral e tratamento atribuídos pelo paciente e família".

\section{A DOENÇA: A PERSPECTIVA CULTURAL DO PACIENTE}

A doença pode ser vista como um desvio social e ser analisada pelo corpo de conhecimentos, crenças e valores, através dos quais ela é definida pelos diversos grupos sócioculturais.

O significado da doença para o paciente e para a sua família inclui as dimensões culturais, sociais e psicológicas dos problemas de saúde e do contexto em que aparece.

Para HELMAN (1994), cada família pode ser considerada como uma pequena unidade da sociedade, com sua própria organização e visão de mundo.

A família é a instituição social que influencia fortemente um indivíduo e poderá determinar o sucesso ou o fracasso da vida do cliente. Se é uma instituição, qualquer disfunção em um dos elementos como a doença, reflete nos demais componentes deste sistema, produzindo mudança em toda a família (FRIEDMAN, 1992).

Os significados são internalizados pelos indivíduos através de processos de interação sóciocultural. Assim, os padrões culturais que as pessoas utilizam para interpretar um dado episódio de doença, são criações sociais, são aprendidos através da convivência com os membros da sociedade em que vive (ALVES, 1993).

A doença é a interpretação, consensual, do grupo sóciocultural sobre a origem e a importância do fenômeno, o efeito deste sobre seu comportamento e o relacionamento com outras pessoas, e também sobre as providências a serem tomadas para contornar a situação.

Qualquer adversidade, como a doença, é normalmente parte integrante das dimensões psicológica, moral e social de uma cultura em particular. A maneira como as pessoas interpretam e respondem aos seus problemas de saúde é muito mais amplo do que ao da enfermidade e devem ser considerados (HELMAN, 1994).

LEININGER (1988) diz que o cuidado profissional é baseado na ciência e na arte humanista, compreendendo comportamentos, funções personalizadas dirigidas para a promoção da saúde e para a recuperação dessa saúde.

Deste modo, "O cuidado humano respeita os valores culturais e o estilo de vida das pessoas e está alicerçado em conhecimentos transculturais apreendidos pela observação da estrutura social, a visão do mundo, os valores, a língua e os contextos ambientais das diferentes culturas" (BARROS et al., 1997, p.11).

A enfermagem contemporânea enfatiza o cuidado, e situa-se para além do tratar, isto é, do visível e do palpável, abrangendo a dimensão afetiva e expressiva dos cuidados, valorizando o potencial de cada um para crescer e desenvolver por si mesmo (BLACK \& MATASSARIN-JACOBS, 1996).

Segundo PERESTRELLO (1982) os fatores sócioculturais em grande parte determinam tanto a apresentação da doença quanto a reação dos outros a mesma. Assim, cada cultura possui sua própria linguagem de sofrimento, que faz a ligação entre as experiências subjetivas de mal estar e o seu reconhecimento social. Os fatores culturais determinam quais sinais e sintomas são percebidos como anormais.

Os profissionais de saúde devem, portanto, estar 
atento para o significado das doenças - como evoluem, como são adquiridas, manifestadas e a sua influência sobre o comportamento do paciente/família, e considerálo na determinação do diagnóstico e tratamento. $\mathrm{O}$ planejamento da assistência terá os seus objetivos atingidos se for considerado o paciente no seu contexto sóciocultural com o significado atribuído pelo paciente à doença e ao tratamento.

\section{METODOLOGIA}

Dentre os métodos de pesquisa qualitativa, a etnografia foi a escolhida. Segundo GERMAIN (1993) o estudo etnográfico é um processo de investigar que utiliza a observação-participante e a entrevista como principais técnicas de coleta de dados. Estes métodos permitem que o pesquisador veja e ouça cuidadosamente o que os atores de uma situação social dizem e fazem.

Na observação-participante, o pesquisador chega a uma situação social com o objetivo de engajar-se na situação, observar as atividades, as pessoas e os aspectos físicos da situação (ZAGO, 1994). O processo é um contínuo ir-e-vir, onde existem momentos de essencialmente observar, observar com alguma participação, essencialmente participar e observar refletindo (GERMAIN, 1993; BOGDAN \& BIKLEN, 1994).

Fizeram parte deste estudo 13 pacientes acometidos pelo aneurisma cerebral, sendo 10 do sexo feminino e 3 do sexo masculino, todos na faixa etária de 30 a 60 anos de idade. A coleta dos dados foram realizadas em três momentos: antes e depois da descoberta do diagnóstico, durante a hospitalização e depois da alta hospitalar, no retorno ambulatorial. As entrevistas foram gravadas com o consentimento formal do informante e com a garantia de anonimato.

Os dados coletados foram registrados logo após cada sessão de observação-participante ou entrevista, em um diário de campo. Os relatos obtidos dos informantes foram transcritos literalmente.

A análise dos dados, foi realizada buscando-se a compreensão do significado cultural da doença e do tratamento do aneurisma cerebral entre o cliente/família.

MINAYO (1993) afirma que o processo de análise de conteúdo relaciona as estruturas significantes com as estruturas de significados dos enunciados. Assim, os conteúdos, ou seja, os dados, são relacionados com os fatores que o caracterizam: variáveis psicossociais, contexto natural e processo de produção da mensagem.

Para GERMAIN (1993), na etnografia o pesquisador inicialmente realiza a análise de conteúdo qualitativo para, através de um processo indutivo, derivar padrões (modelos) ou temas.

A mesma autora explica que o processo de análise dos dados acontece durante todo o período de coleta de dados. A medida que os dados são coletados, processase a sua análise, o que ajuda o pesquisador a traçar metas para as próximas entrevistas.

\section{RESULTADOS E DISCUSSÃO}

A análise dos registros etnográficos, realizaramse em busca o significado do aneurisma cerebral e do tratamento entre os pacientes/famílias. Seguiram os passos preconizados por GERMAIN (1993): codificação - organização dos dados, categorização - agrupamento de códigos similares e derivação de temas culturais.

\section{O TEMA CENTRAL}

As informações obtidas deram origem a três categorias: processo de adoecer, operar a cabeça e sobreviver à cirurgia. A integração entre essas categorias revelou o tema central: "Tinha que ser para mim. Deus sabe o que faz".

Com essa assertiva os pacientes e familiares expõem os seus conhecimentos, crenças, comportamentos e atitudes que permeiam o processo de adoecer, operar a cabeça e sobreviver à cirurgia.

Inicialmente, poder-se-ia considerar que essa assertiva é simplista, pois, todo o processo experienciado pelo paciente/família é fundamentado na crença religiosa. Porém, o processo reflete considerações mais aprofundadas.

No processo de adoecer, as falas dos pacientes/ familiares, sobre a sua doença estabelecem uma relação entre o ambiente e seus problemas pessoais (os três universos: o mundo pessoal, o natural e o sobrenatural): o trabalho excessivo, a fadiga, as crises familiares, a falta de atenção à saúde, e os males físicos. $\mathrm{Na}$ associação desses universos, a experiência da "doença" se consubstancia, torna-se concreta e perceptível para os pacientes e familiares: "Eu andava muito preocupada!", "... ficou doente por desilusão”, “... tinha que ser para mim!”, “Acho que é muito trabalho!”, “... é de familia! Todos nós temos pressão alta!", "O que tem que ser para a gente será!’, “... esse sangue fica parado no corpo e vai para a cabeça!". A concretização é significativa no momento em que provoca interrupções nas atividades cotidianas ou economicamente produtivas, que trazem resultados negativos para a organização da vida da família. É desse modo que o paciente "percebe-se" como doente, quando o senso comum corresponde às condições 
de vida reais do homem comum. Nesse sentido, MONTERO (1985) refere que as imagens associam a saúde à possibilidade do uso instrumental do corpo, e no sentido inverso, a "doença" reflete a impossibilidade do uso instrumental do corpo.

Assim, o “... desmaiei pela dor de cabeça”, “... a cabeça começou a doer inteirinha, ela nunca doeu assim...", são situações inesperadas que desequilibram o cotidiano do paciente/família. Acrescido ao aparecimento súbito dos sintomas, a necessidade de internação e de tratamento cirúrgico de urgência, a espera e as dificuldades para realizar os exames diagnósticos, a situação torna-se subjetivamente complexa. Operar a cabeça que "...é o espigão...”, “...cabeça é cabeça...", “... a parte mais sensivel, especial do corpo...”, “... é tudo...", impõem ao processo de significação da doença, um componente a mais, pois, na cultura popular, a cabeça é a "sede da racionalidade", segundo MONTERO (1985). A família, como a principal rede de apoio para o paciente e de disseminação dos elementos culturais de um grupo, busca no seu contexto, o conhecimento as possibilidades de "reconhecer" a situação. Assim, ela obtém informações de outras pessoas que vivenciam uma situação semelhante e que tiveram uma evolução positiva ou negativa, o que colabora para o conflito: "O sogro dela operou e foi tudo bem", "tenho um cunhado meu que operou, mas ele ficou mais ruim...". O cotidiano da enfermaria, com a convivência com diferentes situações positivas e negativas, em momentos diferentes, acentuam o caos para o paciente/família.

Pelas observações, o caos se confirma com o diagnóstico e a indicação cirúrgica: “...não sei o que vai ser...", quando perspectivas conflituosas surgem, “...eu dei graças à Deus que iam fazer alguma coisa...”.

Neste momento, as explicações dos médicos, sobre a patologia e a indicação cirúrgica, transcendem o caos experienciado pelos pacientes/familiares. Em geral, como retratado por outros estudos antropológicos (MONTERO, 1985; HELMAN, 1994), a fala do médico abstrai o paciente de suas condições reais de existência e falam da doença e do tratamento em termos universais, levando o paciente a um processo de submissão às normas médicas e institucionais. A literatura mostra com clareza que as relações médico/paciente se instituem enquanto relações de poder, e que, por não ser objeto desse estudo, não serão ampliadas.

A situação de caos, conflito ou crise está, então, concretizada.

Resta aos envolvidos, refletir sobre a experiência, e buscar, em si mesmos, alternativas de enfrentá-la, mas dentro do seu contexto cultural.

Estudos antropológicos e sociológicos já analisaram que as terapias alternativas, na cultura brasileira, contrastam-se com a medicina oficial: enquanto esta última explica o "como" das moléstias, as primeiras procuram responder ao "por quê" das enfermidades. MONTERO (1985) complementa que as medicinas alternativas buscam "o sentido" para a situação. As visões religiosas dispõem-se a explicar o sentido da vida, respondendo a um "por quê", que de algum modo justifica os conflitos, o caos da situação de cada pessoa, entre eles, a doença. Através de vários modelos teológicos, as pessoas buscam explicar e justificar a doença.

Pelo tema, "Tinha que ser para mim. Deus sabe o que faz", compreendemos que os pacientes/familiares desvelam que a interpretação religiosa da doença é um acontecimento mais abrangente do que uma disfunção orgânica, contrariamente ao modelo médico que dissocia a experiência do paciente. Com a religião, eles interpretam os sintomas enquanto indicadores de uma situação externa (como vimos em relação aos universos utilizados para pacientes/famílias para explicarem a etiologia da doença) ao paciente, e que se volta contra ele. Para MONTERO (1985) o discurso religioso trabalha com a experiência concreta e subjetiva que o paciente/família têm de sua doença. Portanto, a doença torna-se um acontecimento simbolicamente significativo que organiza a vida de todos os envolvidos.

Considerando-se que os brasileiros têm uma tradição cultural religiosa no catolicismo e que a esperança no "milagre" é um traço característico dessa religião (MONTERO, 1985), podemos compreender que a busca pelo significado da cura-mágica-religiosa, está fundamentada no tema "...Deus sabe o que faz".

Segundo MONTERO (1985) e HELMAN (1994), o fenômeno mágico da cura constitui-se num sistema simbólico que produz um conhecimento sobre o mundo, lhe atribui significados e transformam a situação, os conflitos, o caos. Entretanto, a cura mágica surge como algo que se soma, que se complementa ao tratamento médico. A compreensão da doença e a expectativa pela cura, revaloriza as práticas mágico-religiosas ( "...fizeram promessa. Eu tenho mais é que agradecer a Deus", "...Deus reserva as coisas pra gente e temos que passar, não adianta fugir"), explicando aos envolvidos "o por quê" da situação. Assim, o aneurisma cerebral é interpretado como uma doença material (do corpo) e espiritual (da alma). Assim, a doença material requer intervenção médica (a cirurgia) e a doença espiritual requer a busca da fé religiosa. Embora haja uma distinção formal, não há um confronto real. Essa polaridade leva os pacientes e familiares a buscarem pela complementariedade das duas práticas.

O significado dado a doença e a cirurgia, pelos pacientes e familiares, elaboram-se tendo como referência os parâmetros do discurso, os traços da cultura religiosa do grupo.

Essa significação é extremamente importante para os enfermeiros que buscam fundamentar o "cuidado" 
no contexto cultural do paciente/família. Considerando que o cuidado ao paciente/família com aneurisma cerebral, em todos os períodos operatórios, é complexo e compreende o além do tratar, é importante abranger a sua dimensão afetiva, expressiva e cultural.

\section{CONSIDERAÇÕES FINAIS}

Compreender o significado do aneurisma cerebral e do tratamento entre os pacientes e familiares é um aspecto fundamental para a assistência de enfermagem efetiva. $\mathrm{O}$ enfermeiro precisa apreender a interpretação que o indivíduo confere à doença, que é uma situação considerada "anormal" na nossa cultura.

$\mathrm{O}$ significado que emergiu dos dados evidencia a crença em Deus como indispensável para o enfrentamento de momentos de sofrimento e insegurança. Desta forma, compreende-se que o paciente/família desvelam que a interpretação religiosa da doença é um acontecimento mais abrangente do que uma disfunção orgânica.

O reconhecimento das crenças e da necessidade de cuidado espiritual pode requerer do enfermeiro uma atenção especial às pistas não verbais ou comentários casuais, os quais expressam as preocupações espirituais do paciente.

Acredito que, tentar atender as crenças e práticas religiosas do paciente no planejamento da assistência, pode ser mais uma estratégia para aumentar a disposição do paciente ao aprendizado e também a uma melhor participação no tratamento.

\section{THE CULTURAL MEANING OF CEREBRAL ANEURYSM AND ITS TREATMENT FOR THE PATIENT AND RELATIVES: AN ETHNOGRAPHIC STUDY}

This is a descriptive ethnographic study with 13 patients with cerebral aneurysm and their relatives aiming at understanding the meaning of the illness and the treatment. The data were collected by interviews and observations during the hospitalization and, after the discharge, in the outpatient clinic and at home. The central theme obtained from the study was "It had to be for me! God knows what He does". This theme reveals a religious interpretation for the illness and a magic basis for its cure.Thus, cerebral aneurysm is interpreted as a material illness (body) and a spiritual illness (soul).

KEY WORDS: cerebral aneurysm, culture, surgery, patient

\section{LA COMPRENSIÓN DEL SIGNIFICADO CULTURAL DEL ANEURISMA CEREBRAL Y DEL TRATAMIENTO ATRIBUÍDOS POR EL PACIENTE Y LOS FAMILIARES: UN ESTUDIO ETNOGRÁFICO}

Esta investigación consiste en un estudio etnográfico de los pacientes afectados por aneurisma cerebral y sus familiares, con el objetivo de objetivo de comprender el significado de la enfermedad y el tratamiento. Los datos fueron recolectados por entrevistas y observaciones durante la hospitalización y después del alta en la consulta externa y en la residencia. El tema central obtenido del estudio fue: "Tenia que ser para mi. Dios sabe lo que hace”. Este tema manifiesta una interpretación religiosa para la enfermedad y una fundamentación mágica para el tratamiento. Así, el aneurisma cerebral es comprendido como una enfermedad material (del cuerpo) y una enfermedad espiritual (del alma).

TÉRMINOS CLAVES: paciente con aneurisma cerebral, cultura, cirugía, paciente

\section{REFERÊNCIAS BIBLIOGRÁFICAS}

01. ALVES, P.C. A Experiência da enfermidade: considerações teóricas. Cad. de Saúde Pública, Rio de Janeiro, v. 9, n. 3, p. 263-71, jul/set. 1993.

02. BARROS, M.A. et al. O cuidar de ontem de hoje. Nursing: Revista Técnica de Enfermagem, n. 111. p. 8-13, maio 1997.

03. BLACK, J.M.; MATASSARIN-JACOBS, E. Luckmann \& Forensen. Enfermagem médicocirúrgica: uma abordagem psicofisiologica. Rio de Janeiro: Guanabara Koogan, 1996. cap. 6, p. 589-796.
04. BOGDAN, R.C.; BIKLEN, S.K. Investigação qualitativa em educação. Portugal, Porto, 1994. cap. 2, p. 81-202.

05. DAMIANI, I.T. et al. Diagnóstico e conduta na fase aguda do acidente vascular cerebral. Rev. Bras. Clin. Terapêutica, v. 23, n. 6, p. 219-28, nov. 1997.

06. FOX, J.L. Management of aneurysms of anterior circulation by intracranial procedures. In: YOUMANS, J.R. Neurological surgery. 3. ed. Philadelphia: B. Saunders, 1990. v. 3, cap. 55, p. 1689-1731. 
07. FRIEDMAN, M.M. Family nursing theory and practice. 3. ed. Connectint, Appleton Lange, 1992. cap. 2, p. 21-36: Family nursing: focus, evolution and goals.

08. GERMAIN, C. Etnography: the method. In: MUNHALL, P.L.; OILER, C. (Eds.) Nursing research: a qualitative perspective. New York: National League for Nursing Press, 1993. p. 23768.

09. HELMAN, C.G. Cultura, saúde e doença. Trad. Eliane Mussnich. Porto Alegre: Artes Médicas, 1994. p. 333.

10. HOLANDA, L. et al. Hemorragia meningea. In: . Manual de neurocirurgia. 2. ed. São Paulo: Fundo BYK, 1995. cap. 7, p. 87-95.

11. LEININGER, M.M. Leininger's theory of nursing: cultural care diversity and universality. Nurs. Sci. Q., v. 1, n. 4, p. 152-160, 1988.
12. MELLO, P.A. et al. Doença vascular cerebral hemorrágica. Revista Brasileira de Neurologia, v. 28, n. 5, p. 143-145, 1992.

13. MINAYO, M.C.S. O desafio do conhecimento: pesquisa qualitativa em saúde. 2. ed. São Paulo: Hucitec-Abrasco, 1993.

14. MONTERO, P. Da doença à desordem: a magia na umbanda. Rio de Janeiro: Graal, 1985. p. 274.

15. PERESTRELLO, D. A medicina da pessoa. Rio de Janeiro: Atheneu, 1982. p. 71-132.

16. ZAGO, M.M.F. O ritual de orientação de pacientes pelos enfermeiros cirúrgicos: um estudo etnográfico. Ribeirão Preto, 1994. 153p. Tese (Doutorado) - Escola de Enfermagem de Ribeirão Preto, Universidade de São Paulo. 